\title{
ANALISIS KETERSEDIAAN RUANG TERBUKA HIJAU DAN KECUKUPANNYA DI KOTA DEPOK
}

\author{
(Analysis of The Availability of Green Open Space and Its Adequacy in Depok City ) \\ Faiz Ramadhan ${ }^{1}$, Prima Jiwa Osly ${ }^{1}$ \\ ${ }^{1}$ Program Studi Teknik Sipil Fakultas Teknik Universitas Pancasila \\ E-mail: faizramadhan251@gmail.com
}

\begin{abstract}
ABSTRAK
Penurunan kualitas dan kuantitas Ruang Terbuka Hijau (RTH) berkaitan erat dengan kegiatan perubahan penggunaan lahan dari kawasan bervegetasi menjadi kawasan terbangun. Kota Depok memiliki RTH privat sebesar 40,68\% dan RTH publik sebesar 9,32\% (Bappeda, 2007). RTH privat telah melampaui standar 10\%, sedangkan RTH publik masih lebih kecil dari standar 20\%. Namun demikian, hal ini telah sesuai dengan UU RI No. 26 tahun 2007 dimana RTH minimal 30\% dari luas wilayah.Permasalahan yang ada pada Kota Depok adalah banjir yang terjadi di beberapa Kecamatan di Kota Depok, yaitu Kecamatan Cimanggis dan Sukmajaya, faktor iklim yang seringkali tidak menentu dan minimnya ruang gerak masyarakat, yang menjadi salah satu penyebab meningkatnya tingkat stress atau jenuh bagi masyarakat di Kota Depok. Hal ini mungkin disebabkan penempatan RTH yang tidak merata penyebarannya. Tujuan dari penelitian ini adalah menganalisis RTH Kota Depok dengan pendekatan model Model Indeks kenyamanan berdasarkan faktor iklim mikro melalui Sistem Informasi Geografis dengan beberapa parameter (suhu, Kelembababan, kecepatan angin, titik embun dan penggunaan lahan), Rekomendasi penggunaan lahan berdasarkan factor iklim mikro dan menganalisis hubungan antara indeks tingkat kenyamanan (Temperature Humidity Index) dengan RTH. Pendekatan Model Iklim Mikro menggunakan sistem indeks tingkat kenyamanan (Temperature Humidity Index). Citra Landsat 7 ETM dan Landsat 8 OLI yang diambil pada tanggal 18 dan 22 Oktober 2018, digunakan untuk identifikasi penggunaan lahan yang merupakan parameter utama dan Sistem Informasi Geografis (SIG) digunakan untuk mengkombinasikan seluruh parameter. Hasil penelitian menunjukkan bahwa Kota Depok memiliki luas $5830,478 \mathrm{Ha}$ atau $28,95 \%$ dari total luasan tutupan lahan keseluruhan 20136,5672 Ha sesuai peta administratif Kota Depok. Hal ini Belum sesuai UU RI No. 26 Tahun 2007, dimana proporsi RTH minimal 30\% dari luas wilayah. Serta Kota Depok memiliki Temperature Humidity Index (tingkat kenyamanan) dari masing - masing land use yang dilakukan pengambilan data iklim mikro adalah Area Hutan Kota memiliki THI sebesar $26,99^{\circ} \mathrm{C}$ masuk dalam kategori nyaman, Area Taman Kota memiliki THI sebesar $27,8{ }^{\circ} \mathrm{C}$ masuk dalam kategori tidak nyaman dan Area Kawasan terbangun memiliki THI sebesar $28,61^{\circ} \mathrm{C}$ masuk dalam kategori tidak nyaman.
\end{abstract}

Kata Kunci : Ruang Terbuka Hijau, Iklim Mikro, Kota Depok

\begin{abstract}
The reduction in the quality and quantity of Green Open Space $(R T H)$ is closely related to land use change activities from vegetated areas to built-up areas. Depok City has private RTH of $40.68 \%$ and public green open space of $9.32 \%$ (Bappeda, 2007). Private green space has exceeded the standard of 10\%, while public green space is still smaller than the standard 20\%. However, this is in accordance with RI Law No. 26 of 2007 where green open space was at least 30\% of the total area. The problems that exist in Depok City are floods that occur in several sub-districts in Depok City, namely Cimanggis and Sukmajaya Subdistricts, climate factors that are often uncertain and lack of space for people to move, which is one of the causes of increased stress or saturation for the people of Depok City . This might be due to the uneven distribution of green open space. The purpose of this study was to analyze the Open Space City of Depok with a convenience index model approach based on microclimate factors through a Geographic Information System with several parameters (temperature, humidity, wind speed, dew point and land use), recommendations for land use based on micro climate factors and analyzing the relationship between the comfort level index (Temperature Humidity Index) and RTH. The Micro Climate Model Approach uses a comfort level index system (Temperature Humidity Index). Landsat 7 ETM and Landsat 8 OLI imagery taken on 18 and 22 October 2018, used to identify land use which is the main parameter and Geographic Information System (GIS) is used to combine all parameters. The results showed that Depok City had an area of 5830,478 hectares or $28.95 \%$ of the total land cover area of 20136,5672 ha according to the administrative map of Depok City. This is not in accordance with RI Law No. 26 of 2007, where the proportion of green open space was at least 30\% of the total area. As well as Depok City has a Temperature Humidity Index (comfort level) of each land use which carried out microclimate data retrieval is the City Forest Area has a $\mathrm{THI}$ of $26.99{ }^{\circ} \mathrm{C}$ in the comfortable category, the City Park Area has a $\mathrm{THI}$ of $27.83^{\circ} \mathrm{C}$ in. in the uncomfortable category and the built area has a THI of $28.61^{\circ} \mathrm{C}$ in the uncomfortable category.
\end{abstract}

Keywords: Green Open Space, Micro Climate, Depok City 


\section{PENDAHULUAN}

Menurut UU No. 26 tahun 2007, ruang terbuka hijau adalah area memanjang / jalur / mengelompok, yang penggunaanya lebih bersifat terbuka, tempat tumbuh tanaman, baik yang tumbuh secara alamiah maupun yang sengaja ditanam. Ruang terbuka hijau merupkan bagian dari penataan ruang perkotaan yang berfungsi sebagai kawasan lindung. Kawasan hijau kota terdiri atas pertamanan kota, kawasan hijau hutan kota, kawasan hijau rekreasi kota, kawasan hijau kegiatan olahraga, kawasan hijau pekarangan (Dwihtmojo, Roswidyatmoko 2016). Tujuan pembangunan Ruang Terbuka Hijau merupakan sebagai infrastruktur di wilayah perkotaan yaitu dapat menigkatkan kualitas lingkungan hidup perkotaan yang nyaman, segar dan bersih, sebagai sarana lingkungan perkotaan, menciptakan keserasian lingkungan alami dan lingkungan binaan yang berguna untuk kepentingan masyarakat dan menciptakan kota yang sehat, layak huni dan berkelanjutan (Nirwono, 2017).

Pertumbuhan perkotaan dan urbanisasi menjadi masalah di negara-negara yang sedan berkembang, karena kegagalannya dalam menanggulangi dampak yang timbul. Salah satu masalah perkotaan yaitu perluasan perkotaan dan berkurangnya lahan pertanian. Bagian dari proses kerusakan lingkungan adalah dilahapnya lahan secara besar-besaran oleh persebaran perluasan kota, terutama konurbasi raksasa. Di banyak negara, dengan sumber daya lahan yang populasinya kurang menguntungkan, peralihan lahan pertanian menjadi lahan perkotaan/persebaran industri menjadi masalah yang terpendam. Banyak negara di asia yang menghadapi masalah ini (Nurhayati, Cucu 2017).

Iklim mikro merupakan kondisi iklim pada suatu ruang yang sangat terbatas, tetapi komponen iklim ini penting artinya bagi kehidupan manusia, tumbuhan dan hewan, karena kondisi udara pada skala mikro ini yang akan berkontak langsung dengan (dan mempengaruhi secara langsung) makhluk-makhluk hidup tersebut. Makhluk hidup tanggap terhadap dinamika atau perubahan-perubahan dari unsur-unsur iklim di sekitarnya. Keadaan unsure-unsur iklim ini akan mempengaruhi tingkah laku dan metabolism yang berlangsung pada tubuh makhluk hidup, sebaliknya, keberadaan makhluk hidup tersebut (terutama tumbuhan) akan pula mempengaruhi keadaan iklim mikro di sekitarnya. Antara makhluk hidup dan udara di sekitarnya akan terjadi saling pengaruh atauinteraksi satu sama lain (dikutip oleh Anugrah Teguh Prasetyo dalam Lakitan,2002:53).

Iklim di Kota Depok adalah tropis. Terdapat curah hujan yang signifikan sepanjang tahun di depok, bahkan bulan terkering masih memiliki banyak curah hujan dan suhu rata-rata Kota Depok adalah $26.6{ }^{\circ} \mathrm{C}$ sedangkan curah hujan rata-ratanya adalah $2883 \mathrm{~mm}$ (BPS Kota Depok, 2018).
Berdasarkan data Pemerintah Kota Depok, ketersediaan ruang terbuka hijau yang disediakan oleh pemerintah saat ini baru mencapai $3.721 \mathrm{~km}^{2}$ atau sekitar 16,33\% dari target 30\% ruang tebuka hijau sesuai luas wilayah Depok yang mencapai 20.029 km²(Depok Dalam Angka 2018). Studi ini bertujuan untu mengetahui luasan dan sebaran ruang terbuka hijau di Kota Depok dengan memanfaatkan bantuan aplikasi Sistem Informasi Geografis dan alat Lutron AM-4224 Cup Anemometer/Barometer/Humidity, dalam studi ini dinilai tepat untuk memprediksikan ketersediaan ruang terbuka hijau yang ada, selain itu dapat digunakan untuk memprediksikan ketersediaan ruang terbuka hijau di masa yang akan dating karena dapat memberikan informasi yang akurat, efisien, dan cakupan jangkauan yang luas. Oleh karena itu penelitian ini akan membahas tentang jumlah ketersediaan ruang terbuka hijau di Kota Depok dan Indeks Ketidaknyamanannya.

\section{METODE PENELITIAN}

Penelitian ini dilakukan di 3 kategori Land Use yaitu taman kota, hutan kota dan lahan terbangun, dimana masing-masing Land Use memiliki 3 lokasi pengam bilan data yang berbeda. Waktu pengambilan data penelitian terbagi menjadi terbagi menjadi 3 kategori yaitu : Pagi 05.00 - 07.00 WIB, Siang 12.00 - 14.00 WIB dan Sore 16.00 - 18.00 WIB

Penelitian yang dilakukan adalah uji kondisi Iklim Mikro , dimana jenis data yang di ambil adalah kecepatan udara, kelembaban, suhu dan titik embun untuk menentukan THI yaitu Temperature Humidity Index atau angka ketidaknyamanan. Data primer adalah data iklim mikro melalui observasi atau hasil pengambilan secara langsung di lapangan yaitu: Suhu, Kecepatan udara, Kelembaban dan Titik Embun. Dengan pembagian 3 kategori land use yaitu taman kota, hutan kota dan kawasan terbangun. Data sekunder adalah Citra Landasat 7 ETM dan Landsat 8 OLI Kota Depok yang diambil pada tanggal 18 dan 22 Oktober 2018 yang diperoleh dari hasil pencitraan jauh menggunakan Aplikasi ArcGIS 10.6, Peta Administratif, Peta RTRW Kota Depok tahun 20122032, Luas Wilayah, Jumlah Penduduk, dan Jumlah Ruang Terbuka Hijau yang diperoleh dari Badan Pusat Statistik Kota Depok.

Pengambilan data Iklim mikro (kecepatan angin, suhu, kelembaban dan titik embun) dengan menggunakan bantuan alat Hyelec MS6252A Digital Anemometer, Lutron ME-9000 Type 9 in 1 Stopwacth dan Tripod dilakukan selama 120 menit dengan catatan pembacaan di catat setiap 5 menit. Dalam satu hari pengambilan data dilakukan sebanyak 3 tahapan waktu yaitu pagi pada pukul 05.00-07.00 WIB, siang pada pukul 12.00-14.00 WIB dan sore pada pukul 16.00-18.00 WIB. Setelah data iklim mikro yang didapat dari hasil survey lapangan dan di tabulasi.Perlu diketahui tingkat kenyamanan dari iklim 
mikro yang ada.Fandeli dan Muhammad (2009) menyatakan, untuk memperoleh tingkat kenyamanan secara kuantitatif biasanya digunakan angka Temperature Humidity Index (THI). Dimana THI adalah Temperature Humidity Index atau angka ketidaknyaman, $\mathrm{T}$ adalah suhu udara $\left({ }^{\circ} \mathrm{C}\right), \mathrm{RH}$ adalah kelembaban relative (\%).Batas kenyamanan menggunakan selang kenyamanan berdasarkan Nieuwolt (1997) dan Emmanuel (2005) yang di modifikasi untuk iklim tropis (Effendy 2007). Pada nilai $\mathrm{THI}$ antara $21-24^{\circ} \mathrm{C}$ terdapat $100 \%$ populasi menyatakan nyaman, $\mathrm{THI}$ antara $25-27^{\circ} \mathrm{C}$ hanya $50 \%$ populasi merasa nyaman, serta pada $\mathrm{THI}>27^{\circ} \mathrm{C}$ sebanyak $100 \%$ populasi merasa tidak nyaman.

$$
\mathrm{THI}=0,8 \mathrm{~T}+\frac{(R H \times T)}{500} \ldots
$$

\section{Dimana}

$\mathrm{THI}=$ Nilai Indeks Kenyamanan

$\mathrm{T}=\operatorname{Suhu}\left(\mathrm{C}^{\circ}\right)$

$\mathrm{RH}=$ Kelembaban (\%)

\section{HASIL DAN PEMBAHASAN}

\section{Hutan Kota}

Hutan kota adalah hutan atau sekelompok pohon yang tumbuh di dalam kota atau pinggiran kota. Dalam arti yang lebih luas bisa berupa banyak jenis tanaman keras atau pohon yang tumbuh di sekeliling pemukiman. Hutan kota bisa merupakan hutan yang disisakan pada perkembangan kota atau sekelompok tanaman yang sengaja dibuat untuk memperbaiki lingkungan kota. Hasil rata-rata iklim mikro untuk land use hutan kota di Kota Depok dapat dilihat pada tabel 1. sebagai berikut :

Tabel 1. Hasil Rata-rata iklim mikro pada hutan kota

\begin{tabular}{|c|c|c|}
\hline Jumlah rata-rata & $\begin{array}{c}\text { Temperatur } \\
\left({ }^{\circ} \mathrm{C}\right)\end{array}$ & $\begin{array}{l}\text { Humadity } \\
(\% \mathrm{RH})\end{array}$ \\
\hline Pagi $\quad(05.00-07.00)$ & 25.97 & 76.5 \\
\hline Siang (12.00-14.00) & 33.17 & 47.52 \\
\hline Sore $\quad(16.00-18.00)$ & 27.19 & 83.55 \\
\hline
\end{tabular}

\section{Taman Kota}

Taman Kota adalah taman yang berada di lingkungan perkotaan dalam skala yang luas dan dapat mengantisipasi dampak-dampak yang ditimbulkan oleh perkembangan kota dan dapat dinikmati oleh seluruh warga kota.Hasil rata-rata iklim mikro untuk land use Taman kota di Kota Depok dapat dilihat pada tabel 2. sebagai berikut
Tabel 2. Hasil Rata-rata iklim mikro pada taman kota

\begin{tabular}{|c|c|c|}
\hline Jumlah rata-rata & $\begin{array}{c}\text { Temperatur } \\
\left({ }^{\circ} \mathrm{C}\right)\end{array}$ & $\begin{array}{l}\text { Humadity } \\
\text { (\% RH) }\end{array}$ \\
\hline Pagi (05.00-07.00) & 26.04 & 76.27 \\
\hline Siang (12.00-14.00) & 34.6 & 48.16 \\
\hline Sore $(16.00-18.00)$ & 29.56 & 64.35 \\
\hline
\end{tabular}

\section{Lahan Terbangun}

Ada beberapa jenis penggunaan lahan. Secara garis besar, lahan kota terbagi menjadi lahan terbangun dan lahan tak terbangun. Lahan Terbangun terdiri dari dari perumahan, industri, perdagangan, jasa dan perkantoran. Sedangkan lahan tak terbangun terbagi menjadi lahan tak terbangun yang digunakan untuk aktivitas kota (kuburan, rekreasi, transportasi, ruang terbuka) dan lahan tak terbangun non aktivitas kota (pertanian, perkebunan, area perairan, produksi dan penambangan sumber daya alam). Untuk mengetahui penggunaan lahan di suatu, wilayah, maka perlu diketahui komponen - komponen penggunaan lahannya. Berdasarkan jenis pengguna lahan dan aktivitas yang dilakukan di atas lahan tersebut, maka dapat diketahui komponen-komponen pembentuk guna lahan (Chapin dan Kaiser, 1979). Hasil rata-rata iklim mikro untuk land use lahan terbangun di Kota Depok dapat dilihat pada tabel 3. sebagai berikut :

Tabel 3. Hasil Rata-rata iklim mikro pada Lahan terbangun

\begin{tabular}{|c|c|c|}
\hline Jumlah rata-rata & $\begin{array}{c}\text { Temperatur } \\
\left({ }^{\circ} \mathrm{C}\right)\end{array}$ & $\begin{array}{l}\text { Humadity } \\
(\% \mathrm{RH})\end{array}$ \\
\hline Pagi $\quad(05.00-07.00)$ & 28.87 & 67.96 \\
\hline Siang (12.00-14.00) & 33,70 & 50.58 \\
\hline Sore (16.00-18.00) & 30.96 & 58.57 \\
\hline
\end{tabular}

\section{Penutupan Lahan Kota Depok Tahun 2008 , 2013 dan 2018}

Perubahan tataguna lahan yang terjadi di Kota Depok yang memiliki luas wilayah sebesar 101500 Ha sangat bervariasi. Dalam analisis kali ini tutupan lahan Kota Depok dikategorikan menjadi 3 klasifikasi lahan, yaitu RTH, Lahan Terbuka, dan Lahan terbangun. Untuk lebih jelasnya mengenai perubahan luas tutupan lahan yang terjadi di Kota Depok dapat dilihat pada tabel dibawah ini.

Tabel 4. Luas PerubahanTutupanLahan Kota Depok

\begin{tabular}{|c|c|c|c|}
\hline \multirow{2}{*}{ Klasifiksai Lahan } & \multicolumn{3}{|c|}{ Luas (Ha) } \\
\cline { 2 - 4 } & 2008 & 2013 & 2018 \\
\hline RTH & 18746,955 & 9296,1248 & 5830,478 \\
\hline LAHAN TERBUKA & 14,4332 & 5340,1622 & 2679,2672 \\
\hline LAHAN TERBANGUN & 1376,11 & 5502,5202 & 11626,8242 \\
\hline
\end{tabular}


Sedangkan untuk lebih jelasnya bagaimana perubahan tatagunalahan di Kota Depok dapat dilihat pada gambar layout dibawah ini :

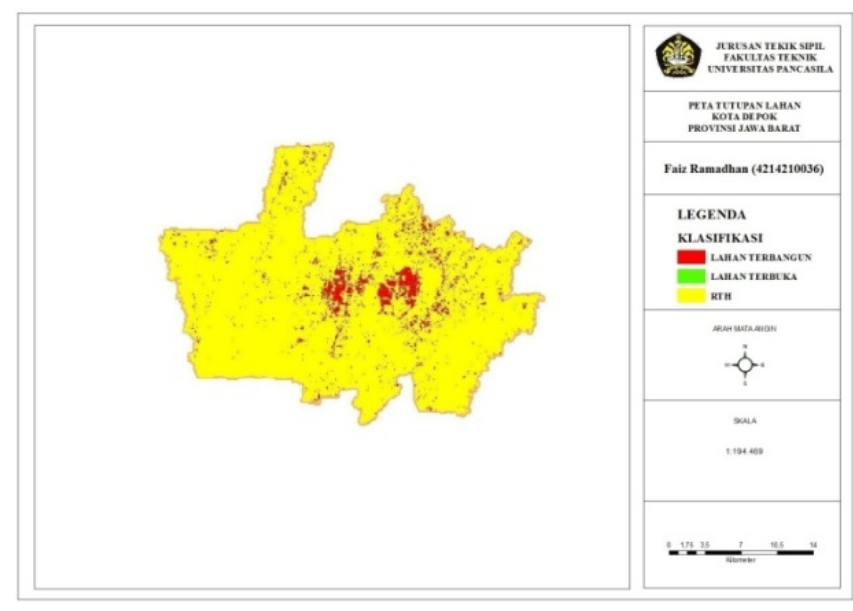

Gambar 1. Perubahan Tutupan lahan Kota Depok pada Tahun 2008

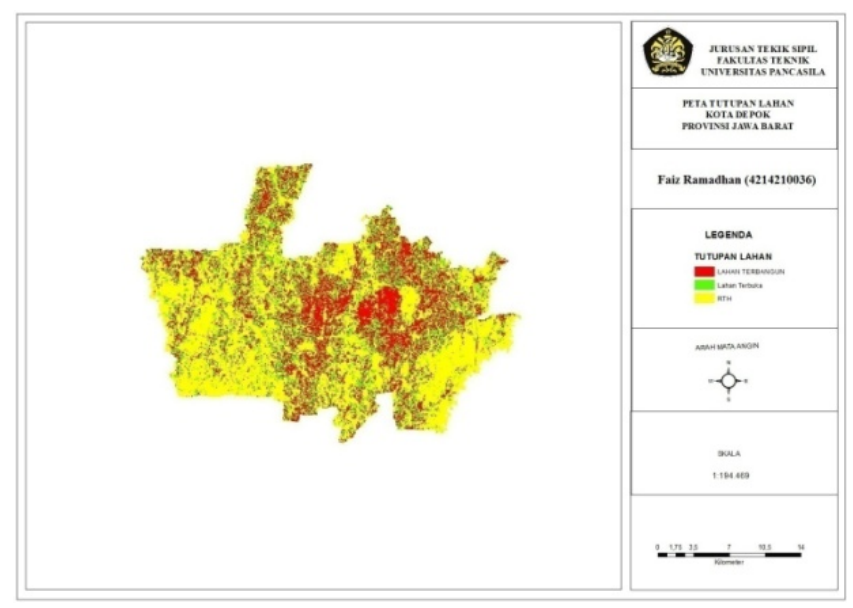

Gambar 2. Perubahan Tutupan Lahan Kota Depok pada Tahun 2013

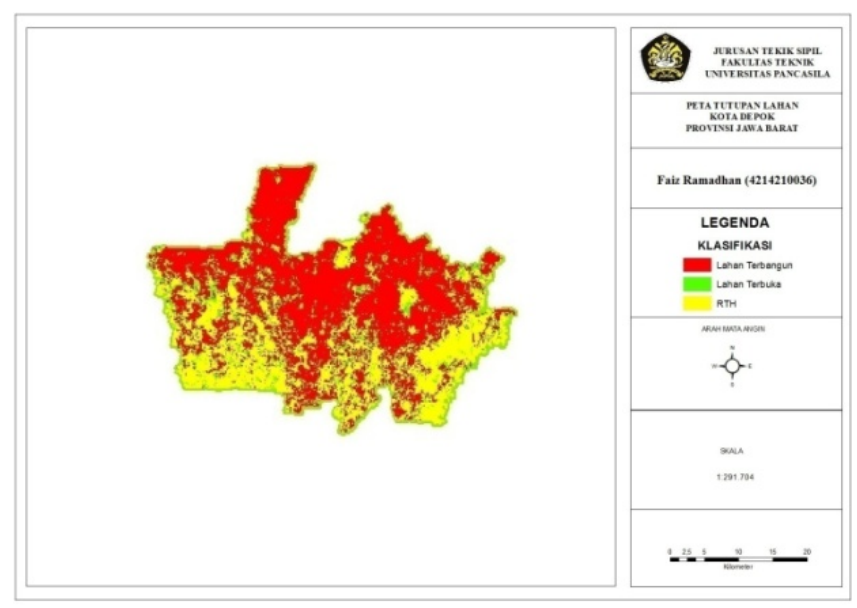

Gambar 3. Perubahan Tutupan Lahan Kota Depok pada Tahun 2018

\section{KESIMPULAN}

Untuk kondisi iklim mikro Kota Depok yang di olah berdasarkan perhitungan Temperature Humidity Index (tingkat kenyamanan) masing - masing land use adalah :

Tabel 5. Kondisi Iklim Kota Depok berdasarkan Temperature Humidity Index

\begin{tabular}{|c|c|c|c|}
\hline Land Use & Waktu & $\begin{array}{l}\text { THI } \\
\left(\mathrm{C}^{\circ}\right)\end{array}$ & Kategori \\
\hline \multirow[t]{3}{*}{$\begin{array}{l}\text { Hutan } \\
\text { Kota }\end{array}$} & $\begin{array}{c}\text { Pagi (05.00- } \\
07.00 \text { WIB) }\end{array}$ & 24,74 & Nyaman \\
\hline & $\begin{array}{c}\text { Siang (12.00- } \\
14.00 \text { WIB) }\end{array}$ & 29,68 & $\begin{array}{c}\text { Tidak } \\
\text { Nyaman }\end{array}$ \\
\hline & $\begin{array}{c}\text { Sore (16.00- } \\
18.00 \text { WIB) }\end{array}$ & 26,29 & Nyaman \\
\hline \multirow[t]{3}{*}{$\begin{array}{l}\text { Taman } \\
\text { Kota }\end{array}$} & $\begin{array}{c}\text { Pagi (05.00- } \\
07.00 \text { WIB) }\end{array}$ & 24,80 & Nyaman \\
\hline & $\begin{array}{c}\text { Siang (12.00- } \\
14.00 \text { WIB) }\end{array}$ & 31,01 & $\begin{array}{c}\text { Tidak } \\
\text { Nyaman }\end{array}$ \\
\hline & $\begin{array}{c}\text { Sore (16.00- } \\
18.00 \text { WIB) }\end{array}$ & 27,45 & $\begin{array}{c}\text { Tidak } \\
\text { Nyaman }\end{array}$ \\
\hline \multirow[t]{3}{*}{$\begin{array}{c}\text { Lahan } \\
\text { Terbangun }\end{array}$} & $\begin{array}{c}\text { Pagi (05.00- } \\
07.00 \text { WIB) }\end{array}$ & 27,02 & $\begin{array}{c}\text { Tidak } \\
\text { Nyaman }\end{array}$ \\
\hline & $\begin{array}{l}\text { Siang (12.00- } \\
14.00 \text { WIB) }\end{array}$ & 30,36 & $\begin{array}{c}\text { Tidak } \\
\text { Nyaman }\end{array}$ \\
\hline & $\begin{array}{l}\text { Sore (16.00- } \\
18.00 \text { WIB })\end{array}$ & 28,39 & $\begin{array}{c}\text { Tidak } \\
\text { Nyaman }\end{array}$ \\
\hline
\end{tabular}

Jumlah tutupan lahan RTH di Kota Depok yaitu $(5830,478 \mathrm{Ha} / 28,95 \%)$ masih belum cukup karena belum sesuia dengan UU No. 26 Tahun 200.

\section{REFERENSI}

Alika,Nur. (2017). Analisis Ketersediaan Ruang Terbuka Hijau Di Kota Serang Tahun 20002015. [skripsi].Jakarta (ID): Universitas Islam Negeri Jakarta

Instruksi Menteri Dalam Negeri No.14 Tahun 1998 Tentang Fungsi Ruang Terbuka Hijau

Kota Depok Dalam Angka 2018. Depok : Badan Pusat Statistik Kota Depok

Masruddin, Fahril. (2017). Analisis Pengelolaan Ruang Terbuka Hijau Di Kota Bau Bau. [skripsi].Makassar (ID): Universitas Hasanuddin

Nofalina,Tety. (2010). Analisis Ruang Terbuka Hijau Kota Depok Dengan Pendekatan Model Konservasi Air Melalui Sistem Informasi Geografis. [skripsi].Bogor (ID): Intitut Pertanian Bogor

Peraturan Menteri Dalam Negri No. 1 Tahun 2007 Tentang Penataan Ruang Terbuka Hijau Kawasan Perkotaan
Peraturan Menteri Pekerjaan Umum Nomor:05/PRT/M/2008 Tentang Tujuan Penyelenggaraan Ruang Terbuka Hijau


Peraturan Menteri Agraria dan Tata Ruang No.25 Tahun 2015 Tentang Penyebaran Penduduk Indonesia

Prasetyo Teguh. (2002).Pengaruh Ruang Terbuka Hijau (RTH) Terhadap Iklim Mikro Di Kota Pasuruan.Vol. 53. Cited in http://jurnalonline.um.ac.id/data/artikel/artikelCB4E6C3DB8 AAF0E1605A9A9DB462650A.pdf. November 2018].
Roswidyatmoko. Dwihatmojo (2016). Kajian Ruang Terbuka Hijau di Kecamatan Serpong, Kota Tangerang. Jakarta.

Undang-Undang No. 26 tahun 2007 dan Peraturan Menteri No. 69 Tahun 2013 Tentang Terbuka Hijau

Widya Aurelia. (2011). Analisis Perubahan Luas Ruang Terbuka Hijau Dan Faktor-Faktor Yang Mempengaruhinya Di Jakarta Selatan [skripsi].Bogor (ID): Institut Pertanian Bogor 